\title{
Patricio Aylwin Azócar en sus palabras: La oposición "jurídica" contra el gobierno de la Unidad Popular y el colapso de la línea del "camino propio" del Partido Demócrata Cristiano (1970-1973)
}

\section{Diego Hurtado Torres ${ }^{1}$}

La presente selección de textos de Patricio Aylwin dista mucho de formar parte de una "historia B" u "oculta" de su actuación en el proceso político que tuvo a la Unidad Popular (UP) en el gobierno de Chile entre 1970 y 1973. El lector interesado en profundizar sus conocimientos sobre este tema, podrá hallar en el sitio web de la Biblioteca del Congreso Nacional de Chile el registro digitalizado de las sesiones del Senado que extractamos aquí. ${ }^{2}$ Junto a la recuperación de estas fuentes parlamentarias -cuya publicación en diarios de circulación nacional, por lo demás, era una práctica común en el Chile de los 1970 y antes- hemos desempolvado de archivos periodísticos dos entrevistas que se ubican, respectivamente, en ambos extremos del período. Apoyándonos en estos documentos y, el deber nos obliga a decirlo, en la investigación que sirvió de sustento a nuestra Tesis para optar al grado de Magíster en Historia por la Pontificia Universidad Católica de Chile, "Las palabras no se las lleva el viento: lenguajes políticos y democracia durante el gobierno de la Unidad Popular (1970-1973)", nos atrevemos a conjeturar que Patricio Aylwin encarnó la vida y ocaso de una estrategia particular dentro del mundo opositor que se fue formando contra la UP. Lo distintivo de esa estrategia, constituida por el Estatuto de Garantías Constitucionales en 1970, las presiones sobre Allende durante 1971 y 1972 para que convocara a un plebiscito constitucional y las conversaciones de 1973 buscando que el Presidente rectificara su gestión y el gobierno de la UP se ordenara a la ley, es materia del análisis introductorio que propongo a continuación. Con el afán de simplificar la tarea de los lectores, he optado por fragmentar los textos aquí recomendados tratando de no herir su comprensibilidad, su capacidad de reflejar ni su atractivo intrínseco.

1 Chileno. Magíster en Historia, Pontificia Universidad Católica de Chile, Estudiante del Programa de Doctorado, University of Maryland, Estados Unidos. El autor agradece a los profesores Joaquín Fermandois Huerta y Sebastián Hurtado Torres por las conversaciones y el estímulo intelectual y en don Roberto Gutiérrez a todos los trabajadores de la Biblioteca Nacional de Chile que hacen posible la labor de los historiadores.E-mail: dhurtado@uc.cl

2 Ver http://historiapolitica.bcn.cl/historia_legislativa 
Cuando Salvador Allende obtuvo la mayoría relativa en la elección presidencial del 4 de septiembre de 1970, Patricio Aylwin se aproximaba a cumplir 52 años. Era ya entonces un hombre que había recorrido un buen trecho de su vida adulta. Sensible a la evolución de la política mundial durante el siglo XX -cruzada por el surgimiento y la derrota de los fascismos europeos y el nacimiento de un orden global en el que la democracia liberal y el comunismo se confrontaban en cuanto "sistematizaciones del mundo" alternativas, totales y excluyentes, aunque ambos polos fueron recíprocamente permeables en el singular caso de Chile-, llegó a ser un actor distinguido de la democracia chilena como encumbrado dirigente de la Falange Nacional (a la que entró en 1946) y de la generación que fundó en 1957 y llevó al poder al Partido Demócrata Cristiano (PDC) bajo la Presidencia de Eduardo Frei Montalva entre 1964 y 1970. Combinaba sus responsabilidades políticas con una rigurosa carrera profesional como abogado y profesor universitario. En marzo de 1965 fue elegido senador en representación de la sexta agrupación que reunía a las provincias de Curicó, Talca, Linares y Maule, sus tierras familiares. Desde este sillón promovió, entre otras leyes, la transformación constitucional del derecho de propiedad y la reforma agraria. La vida deliberativa del Senado, en cuyo seno en buena parte se fraguaron los cambios que señalarían los pasos del país bajo el régimen de la Constitución de 1925, le calzaba como al profesor le resultan naturales los libros. Su carácter, moldeado por una familia de padre masón-juez de la República y por una educación vigorosamente jurídica y, quizás, la profunda religiosidad cristiana que le venía de su ascendencia materna, lo orientaban a prestar obediencia categórica al imperio de la ley, un rasgo que por lo demás no era propio solo de Aylwin (Serrano y Cavallo, 2006: 95-109).

En efecto, la "cultura jurídica" sobre la que se asentaba el régimen de 1925, más liberal que otra cosa, constituía el pórtico de ingreso a la arena pública por el cual todos los lenguajes políticos de la "democracia clásica" del período 1932-1973 debían atravesar. Incluso el proyecto de transformación marxista de la Unidad Popular, la llamada "vía chilena" al socialismo, tuvo que sujetarse a ese lenguaje "legalista". No obstante esta cuasi absorción del habla marxista por el sistema democrático, el resultado de 1970 propinó un golpe duro, mezcla de realismo y psicologismo, tanto a la convaleciente derecha política del momento como al mundo socialcristiano que tendría que hacer abandono del poder (Fermandois, 2013: 75-103).

Aylwin, quien dentro del partido se identificaba con el freísmo -aunque para los instantes posteriores al triunfo de Allende hay que distinguir entre el freísmo del Ejecutivo, que como su líder se tienta con un desquiciamiento institucional, y el freísmo dentro del Parlamento, mucho más pragmático y dueño de sí mismo- (Hurtado Torres, 2013: 105-140) y la línea del "camino propio", participaba de la desconfiada conciencia sobre los fines históricos y el programa de acción de la Unidad Popular que se apoderó, en muchos casos 
rozando la paranoia, de la mayor parte de los antagonistas de la coalición marxista. Ese recelo, sin embargo, no lo llevó más que a defender posiciones, hablando éticamente, estrictamente políticas, es decir, afirmadas en el uso de la palabra, la estabilidad de la promesa y el límite de la negociación. En la escala de aprensiones que se apoderaron de los dirigentes del Partido Demócrata Cristiano luego del triunfo de Allende, puede decirse que Aylwin albergaba muchas más que Radomiro Tomic, el derrotado candidato presidencial del Partido, el senador Renán Fuentealba o el diputado Bernardo Leighton -por nombrar a los principales dirigentes que tenían una tendencia de izquierda-, aunque sin dejarse dominar por la paralizante desesperación que el Presidente Eduardo Frei terminó transmitiendo a su entorno más cercano en el Ejecutivo durante las semanas que precedieron al Congreso Pleno que debía elegir al Presidente del período 1970-1976 entre Allende y Jorge Alessandri. Aylwin no fue un conspirador en este momento de nerviosismo ni tampoco se le ocurrió serlo. En lugar de esto, encabezó las tratativas que prosperaron en la reforma constitucional acordada por el Partido Demócrata Cristiano y la Unidad Popular, más conocida como Estatuto de Garantías Constitucionales. Este acuerdo aseguró el apoyo del PDC a Allende en el Congreso Pleno a cambio de un evanescente compromiso sobre respetar la democracia adquirido por el nuevo Presidente.

El papel desempeñado por Aylwin en esta tumultuosa urdimbre quedará expuesto en los dos primeros extractos que componen esta selección. En primer lugar, incluimos la mayor parte de la entrevista que el senador democratacristiano concedió al periodista de La Segunda Hernán González Valdebenito poco antes de que se aprobara el Estatuto en el Senado, si bien ella fue publicada un día después de concretado ese hito. Además de hablar largo y tendido sobre la razón de ser del Estatuto, motivo que nos lleva a incluir la conversación en nuestra selección, Aylwin se refería a asuntos de índole partidaria, sosteniendo severas críticas a la candidatura de Tomic y señalando sus discrepancias frente a la conducción del Presidente del PDC Benjamín Prado. Podría conjeturarse, con la ventaja de tener a la vista las desoladoras consecuencias del proceso democrático que entonces iniciaba un nuevo ciclo, que Aylwin ejerció una oposición desproporcionadamente dura en los inicios del gobierno de la Unidad Popular. Nos parecería una apreciación injusta. En la Junta Nacional citada para resolver la conducta del Partido de cara al Congreso Pleno, ocurrida el 3 y 4 de octubre de 1970, Aylwin abogó a favor de presentar un proyecto de reforma constitucional propio, en el cual la UP no incidiría, pero que tendría que suscribir si quería los votos del PDC en el Congreso Pleno. La corriente mayoritaria del Partido, quizás temerosa de un mal mayor, optó por una estrategia conciliadora que zanjó que el PDC haría partícipe a la UP del texto de la reforma constitucional. A pesar de la derrota de su tesis, fue Aylwin el responsable de la redacción del Estatuto. En su elaboración, además de ser asesorado por juristas y constitucionalistas cercanos al PDC como Enrique Evans, Francisco Cumplido, Gustavo Lagos y 
Guillermo Piedrabuena, consultó la opinión de los jefes militares, entre los que René Schneider y Carlos Prats destacaban como los más convencidos de la necesidad de lograr el consenso (Prats, 1987: 165-189; Serrano y Cavallo, 2006: 163-178; González, 2012: 75-99).

El Estatuto, denunciado con irritación por los nacionales que no habían sido considerados en la negociación y devaluado por la izquierda que sentía que no tenía que llegar a transacción alguna en la hora de su victoria, fue un pacto gélido. Aylwin no escondía sus suspicacias relativas a que la experiencia de la Unidad Popular, orquestada por el "sovietincha" Partido Comunista y con un Allende atrapado entre su promesa democrática y su promesa revolucionaria, deviniera en un caso más de totalitarismo comunista en el mundo. Temía que los procedimientos del comunismo desbordaran la democracia representativa vigente en Chile y le otorgaran alguna ocasión a los sectores «totalitarios» de la UP para asestar un "golpe de Praga" (Gaddis, 2005: 32-34). ${ }^{3}$ El telón de fondo de esta sospecha era el abismo conceptual sobre lo político y la democracia que separaba al liberalismo del marxismo y la disparidad táctica surgida entre una izquierda que trataba de soslayarlo -exaltando su capacidad de diluir el lenguaje de la revolución en el lenguaje de la democracia-y una oposición en ciernes que difería sobre la intensidad y los medios por los cuales declararlo. Con todo, junto a lo maniobrático del Estatuto, en la promesa de Allende de entender sus disposiciones como "la regla moral de un compromiso ante nuestra propia conciencia y ante la historia" ${ }^{4}$ y en la orientación misma de la reforma -ella afinaba el conjunto de derechos garantizados por la Constitución y la definición de "fuerza pública", basándose en su mayor parte en debates y proyectos de reforma constitucional que, si bien habían fracasado durante la segunda mitad de los 1960, formaban la historia reciente del diálogo democrático, cuestión que indica que el Estatuto no era un artilugio surgido de la nada- podrían haberse hallado dos puntos de encuentro que ampararan al proceso político frío que, como lo mostró el atentado contra el general Schneider, surcaba un "mar violento".

El mismo día del alevoso crimen, el jueves 22 de octubre de 1970, el Estatuto fue aprobado por el Senado. Apreciado por Aylwin como un "ring democrático", veremos en el segundo extracto, correspondiente a esa sesión de la Cámara Alta, al senador democratacristiano enfrascarse en un debate con sus pares nacionales Víctor García y Francisco Bulnes sobre la noción de libertad de enseñanza y la autonomía universitaria. A nuestro juicio, este

3 Entre febrero y junio de 1948, el Partido Comunista Checoslovaco, apoyado por la Unión Soviética, provocó la dimisión del Presidente constitucional Edward Benes, la muerte del Canciller Jan Masaryk e hizo aprobar, reprimiendo y silenciando a la oposición, una nueva Constitución por la que Checoslovaquia se convirtió en un estado socialista. 
intercambio muestra con toda su modestia que el Estatuto también persiguió concordar una mirada conjunta del país a mediano plazo, al menos según la inspiración que le atribuyó el PDC. Mucha concesión para espíritus revolucionarios, poca cosa para espíritus de reacción, la creatura de Aylwin terminó limitada a infundir carácter a un tipo entre otros de oposición contra el gobierno de la Unidad Popular, a la que hemos denominado «jurídica» en virtud de su apego a los argumentos de derecho, el lenguaje institucional y las prácticas deliberativas del Parlamento y la opinión pública.

En este entorno, más o menos prevaleciente hasta el estallido del Paro de Octubre de 1972, Aylwin llevaba la voz cantante. Como presidente del Senado (lo fue entre enero de 1971 y mayo de 1972) lideró con tenacidad las presiones al gobierno para que convocara a un plebiscito constitucional que dirimiera el conflicto creado por la reforma opositora de las Tres Áreas de la Economía. Prueba al canto es el discurso que Aylwin pronunció en la «Marcha de la Democracia» del 12 de abril de 1972, en el que sostenía:

"La democracia se funda en principios morales, el primero de los cuales es el respeto a la verdad. El país tiene derecho a saber la verdad, a que se expliquen todas las situaciones ambiguas que despiertan fundadas sospechas en la opinión pública, que el señor Presidente de la República se defina claramente. Y tiene derecho a exigir que el Gobierno escuche la verdadera voluntad del pueblo, libremente expresada por los cauces constitucionales. Si el Gobierno sigue creyendo que la suya es la voluntad mayoritaria, consulte a los chilenos a través de un plebiscito. Si, por cualquier causa, prefiere rehuir el plebiscito, acepte la voluntad mayoritaria expresada en los últimos comicios y representada en el Congreso Nacional. Nadie le pide que abdique de su programa. Solo exigimos que para su cumplimiento se someta a los cauces de la Constitución y las leyes, aceptando las reglas del juego democrático. No estamos aquí para impulsar ninguna sedición ni forma alguna del fascismo. Lo sedicioso y fascista es desconocer la voluntad mayoritaria del pueblo y pretender imponer a la fuerza un sistema de vida que la mayoría del país reclama. Sepa el Gobierno y sepa Chile entero, que defenderemos la democracia por los caminos de la democracia. Pero que nada ni nadie nos ablandará ni amedrentará. Y con los corazones y las voluntades de la inmensa mayoría de los chilenos amantes de la libertad y creyentes en el derecho, triunfaremos" ${ }^{5}$

Tras el rechazo por el Senado de las observaciones presidenciales a la reforma en julio de 1972, Allende, en una decisión anómala para una situación ya anómala, dilató la resolución del asunto hasta 1973, llevándolo

5 El Mercurio, 13-IV-1972. 
ante el criterio del Tribunal Constitucional. Después de que este se declaró incompetente en la materia, promulgó parcialmente la reforma constitucional en las partes sobre las que no había controversia mediante decreto enviado a la Contraloría (Silva Cimma, 2008: 149-ss).

En el extracto $N^{\circ} 3$, compuesto por partes de la intervención de Aylwin en la sesión del Senado del 6 de octubre de 1972, se podrá apreciar con nitidez la mentalidad de una oposición que, si traducimos correctamente la postura del legislador democratacristiano, entendía perfectamente que la revolución consiste en aglutinar fuerzas y empujar la realidad social convulsionada hasta los linderos de la normalidad donde se catapultan la costumbre y el sello de la ley. No interpretamos de otra forma las denuncias sobre el maltrato económico de que estaba siendo objeto la "Papelera", emblema de la libertad de expresión y principal piedra de tope en el casi acuerdo entre Allende y el PDC presidido por Fuentealba a mediados de 1972, al fijársele precios de venta bajo sus costos de producción; la "desviación de poder" que suponía el uso abusivo de los "resquicios legales" por parte del Ejecutivo; la posibilidad de que en Chile ocurriera lo mismo que en Checoslovaquia en 1948; y la decepción que había provocado Allende al desestimar el Estatuto como una "necesidad táctica" frente al intelectual guevarista Régis Debray cuando se suponía que lo había adoptado como "palabra de honor" frente a sus opositores. ${ }^{6}$ Incluso, llegaba tan lejos como a acusar la "ilegitimidad" del gobierno de Allende. Eran los albores del Paro que clausuraría la fase tipo "juego de ajedrez" por la que el ciclo democrático se había deslizado desde septiembre de 1970. La movilización pro y anti UP que supuso la crisis de 1972-1973, refrendada esta por la presencia de los militares en el gabinete de Allende desde noviembre de 1972, desbordó la política tradicional -aquella que se expresa en la jerarquía de la representatividad y de los partidos políticos, los opositores por ese entonces estaban aliados bajo las insignias de la Confederación de la Democracia (CODE) - y, para lo que nos importa, redistribuyó los equilibrios del poder al interior de la oposición dando bríos, en intereses y capacidad de presión, a sectores gremialistas vinculados al tejido de un golpe que se había ido imbricando desde 1970 (Valenzuela, 1989: 210-289; Fermandois, 2013: 557-582).

Si bien Patricio Aylwin ganó con claridad su reelección como senador en los comicios parlamentarios del 4 de marzo de 1973 y poco más tarde, afirmando una línea de confrontación, desplazó de la dirección del Partido a Renán Fuentealba, era difícil que los procedimientos representativos pudieran variar el ambiente contrario a los acuerdos que campeaba por doquier y que empezó a rebasar la democracia el 29 de junio de 1973, cuando se dejó

"Allende habla con Debray", en Punto Final, 126, 16-III-1971: 58. 
caer, en la muestra más agresiva producida hasta entonces de la impaciencia volcánica que corroía a una parte de la clase militar, el "Tanquetazo". Simbólicamente, durante la tarde de ese día Aylwin concurrió al Congreso junto a otros correligionarios y senadores del Partido de Izquierda Radical (PIR) y el Partido Comunista (PC) a manifestar su oposición contra el intento de sublevación de Souper. Esta breve declaración es el cuarto documento de los que componen nuestra selección. Al político no le quedaba más que bregar contra la fuerza de que suelen revestirse lo inevitable y la violencia en política, especialmente cuando esta atraviesa momentos críticos.

De ahí que haya consentido en dialogar con Allende, a pesar de saber debilitada la autoridad del Presidente sobre los sectores más intransigentes de la UP, haber sufrido la decepción del Estatuto y conocer al dedillo las habilidades, proverbialmente célebres en los corrillos políticos, de la "muñeca" de Allende en las negociaciones. Así, cuando representó al Partido Demócrata Cristiano en las conversaciones con el Presidente -a fines de julio (versión pública) y mediados de agosto (versión privada)- para tratar de alcanzar una rectificación del gobierno, era difícil creer que estuviera representando a toda la oposición. Los mundos de la derecha -el político y el gremial-no aceptarían quedarse por segunda vez fuera de la partida tal como había ocurrido durante la gestación del Estatuto, eco a su vez de la espiral que dominó la política chilena desde mediados de los 1960. La gravitación de la derecha elevaba el precio de lo que Aylwin podía negociar -algo similar podría decirse de Allende y el sector rupturista de su gobierno- $y$, por lo demás, ni siquiera contaba con la anuencia de Eduardo Frei con todo su peso dentro del Partido. Como se sabe, los encuentros entre Allende y Aylwin ni apaciguaron los ánimos caldeados ni produjeron una sola concesión entre gobierno y oposición. Los valores asociados al tiempo como la espera y la paciencia habían sido sustituidos por sus contrarios: la inmediatez y la desesperación.

En la pieza $N^{\circ} 5$ de esta selección aparece un Aylwin que rumia este fracaso a través de una escueta entrevista otorgada a la revista Qué Pasa, aunque por su formato -el periodista, cuyo nombre no sabemos, incluye una crónica sobre la fallida negociación con el Presidente Allende y una breve biografía del senador- da la sensación de que las palabras del líder del PDC no son otra cosa que la parte explícita de una narración que parece haber sido adecuada para dar sentido y relieve a su postura en la apremiante situación política del momento. Aylwin acertaba a poco más que reconocer el agotamiento de la estrategia de oposición que había conducido. Señalaba -como también lo hacían políticos marxistas en confesiones de pureza doctrinaria- que gobierno y oposición hablaban «lenguajes distintos», justo todo lo que él había tratado de contradecir durante y a través de su vida política apegada a la legalidad, la representatividad parlamentaria, las prácticas propias de un sistema de partidos y la mínima común lógica que estos factores entrañan. En el fondo, 
no era solamente un traspié personal, sino que -a nuestro modo de ver- el último estertor de una forma de comprender la política que subyacía al modus vivendi del sistema democrático de 1925.

Lo que vino después -las sucesivas crisis ministeriales, el Acuerdo de la Cámara de Diputados del 22 de agosto de 1973, las últimas maniobras entre Allende y el PDC, y en definitiva el Golpe de Estado- solo puede entenderse distinguiendo entre una oposición "jurídica" que ha perdido la iniciativa y termina por entregar la posta lanzando un ultimátum -me refiero al Acuerdo de los diputados cuyo texto final Aylwin incluso logró morigerar- a un Presidente revolucionario que no iba a renunciar ni a su programa ni a su filosofía de la historia, y una oposición "prepolítica" que no estaba dispuesta a esperar ni a cooperar en acuerdos que consideraba fantasiosos y de los que, por lo demás, se sabía excluida. El Golpe sorprendió a Aylwin elucubrando pasos y sobrepasado, inclusive por las bases del Partido Demócrata Cristiano, pero sobre todo por el peso de los hechos y la eficacia de las armas.?

Aunque no se conocen en profundidad las reflexiones más íntimas de Aylwin en los días alrededor del 11 -lo que nos impide afirmar taxativamente cuándo se resignó a apoyar el golpe de Estado-, ellas pueden suponerse en una encrucijada de largo plazo donde confluían al menos tres crisis distintas, pero que se entrelazaban: la del sistema de 1925, la de la UP -ambas puestas de relieve por Genaro Arriagada- (Arriagada, 2003: 129-142) y la del propio PDC. Esta última hecatombe situó a Aylwin, tal como a otros destacados dirigentes del Partido, ante la disyuntiva que se abría entre la inconsistencia doctrinaria que significaba validar la intervención de las fuerzas armadas en el proceso democrático y la «necesidad estratégica» de incidir en el régimen militar que administraría el caótico estado general del país. Como se sabe, Aylwin y la vertiente oficialista del PDC optaron por una interpretación explicatoria y adaptativa del Golpe ${ }^{8}$ en contraste con la interpretación categórica y condenatoria que suscribió el llamado "Grupo de los 13" liderado por Bernardo Leighton (Donoso y Dunlop, 2013: 11-13). Esta bifurcación de declaraciones desnudaba la lábil posición estratégica del "camino propio" -y la "solución" del comunitarismo, su correlato intelectual- en el contexto del enfrentamiento entre revolución y contrarrevolución y del PDC sin combinarse programática ni proyectualmente con la izquierda o la derecha. Con el paso del tiempo y el descorrimiento del velo que encubría a una dictadura edificada sobre la anomia y la fractura

7 Considérese el extracto del discurso, fechado el 8-IX-1973, en que Aylwin reconocía que el Partido estaba en una "posición sobrepasada" por los gremios. Apareció en El Mercurio, 14-XII-2014, a causa de los preparativos de la publicación de los papeles personales de Patricio Aylwin.

8 La declaración oficial del PDC salió publicada en La Tercera, 13-IX-1973. 
de la paz, Aylwin empezó a reconocer que había «pecado de ingenuidad» al creer en la transitoriedad del nuevo régimen, retrospectiva que no está exenta de tensiones ni oscuridades, volcándose luego a la oposición contra el hierro de Pinochet (Aylwin, 1998: 34).

\section{Fragmento $\mathrm{N}^{\circ}$ 1:}

"'Errores e indefinición de Tomic causaron su derrota", La Segunda, 23-X-1970, pp. 8-9.

Por Hernán González Valdebenito.

\section{P. -Usted defendió en la última Junta Nacional del PDC una moción que fue derrotada por sólo ochenta votos y que daba por terminadas las conversaciones con la Unidad Popular. ¿Sigue usted creyendo que ese conjunto de partidos que apoya a Salvador Allende no da garantías suficientes?}

R. - En realidad, el voto defendido por mí no sostenía que esos partidos no dieran suficientes garantías. Lo que sostenía más exactamente era que las respuestas dadas por Allende y por la Unidad Popular hasta el momento de celebrarse esa Junta no eran satisfactorias. Por una parte, porque no aceptaban de inmediato elaborar o consagrar el estatuto constitucional de garantías democráticas tal como nosotros lo habíamos pedido, "se corrían" en cierto modo.

En segundo término, porque no valorizaban o no apreciaban con realismo la situación política: Allende obtuvo el 36 por ciento, y eso le daba el mejor título para ser elegido, pero para ser Presidente necesita el 51 por ciento del Congreso Pleno, ya que no lo tuvo en las urnas. Sin embargo, las respuestas de Allende y de la Unidad Popular no eran las respuestas de quien necesita un 14 por ciento más para ser elegido en el Congreso Pleno y que debe tratar con otros de quienes justamente requiere su aporte; por el contrario, eran las respuestas de quien se sentía ya elegido y que le decía a alguien de la oposición: "Miren, ustedes me piden tales y cuales reglas de juego; conforme se las voy a dar, pero ello importaba prácticamente dar por hecho su elección. La carta de Allende en ese sentido es muy clara y la respuesta de la Unidad Popular no despejaba esa sensación. A mí me parecía que nosotros no podíamos aceptar ese plano de negociaciones.

En tercer lugar, aun cuando Allende fue muy claro en la conversación que tuvo con nosotros para decir que valorizaba enormemente el apoyo del PDC en el Congreso Pleno para su elección -aun en el evento de que no la necesitara-, en el hecho las respuestas importaban una subestimación o un desconocimiento de ese valor. 


\section{P. - ¿Era "sobradora" esa respuesta?}

R. -En el fondo era la posición de quien dice: "yo ya estoy elegido, pero estoy de acuerdo en tratar con ustedes tales o cuales cosas", situándose en la condición de ya elegido, en circunstancias de que aún faltaba el pronunciamiento en el parlamento. A mi juicio la democracia cristiana no debía aceptar un predicamento de esa especie.

Yo creo en la trayectoria democrática de Allende y estoy seguro de que él no quiere salirse de las normas democráticas, pero dentro de los partidos que apoyan a Allende hay sectores que entienden la democracia de una manera muy diversa a como nosotros la entendemos. Por formación doctrinaria, por mentalidad, por modo de ser, tienen ciertas tendencias totalitarias. Eso existe en los grupos de ultraizquierda y existe también, según lo ha probado históricamente dondequiera que ha triunfado -incluso en Chile en cada lugar donde ha tomado puestos de control- el Partido Comunista. Están allí las experiencias de la Universidad Técnica, del Canal 9 de televisión, del Instituto Pedagógico y de diversos otros lugares donde, instalado el Partido Comunista en el poder, empieza a usar procedimientos que van excluyendo a todos los demás para tomar ellos en sus manos el monopolio del poder.

Creo que frente a eso, aunque Allende quiera gobernar en democracia, es indispensable asegurarse ciertas reglas de juego que eviten que estos sectores impongan su estilo a la vida política chilena.

\section{P. - ¿Usted cree, entonces, en la efectividad de las garantías solicitadas por el PDC, que el diputado nacional Fernando Maturana calificó como "diques de papel"?}

R. -Creo que el diputado Maturana está haciendo un juego político oportunista bastante barato. Estimo que las garantías -y quien las lea y las examine lo comprobará- son efectivas y muy importantes. Dondequiera que triunfan los sectores marxistas comienzan de inmediato a aplicar sus métodos: suprimen el pluralismo partidista, eliminando a todos los partidos de oposición; acaparan todos los medios de comunicación de masas en sus manos y cierran la prensa, la radio y la televisión a quienes discrepan con ellos; descabezan y politizan a las Fuerzas Armadas y crean, por otro lado, milicias populares: estatizan totalmente la educación y le imponen una ideología oficial, de manera que la educación pasa a convertirse en un instrumento de formación ideológica de las juventudes y de la niñez; a base de organización política o comités de base, constituyen poderes que, de hecho, se sobreponen a las autoridades legalmente constituidas: al lado de cada autoridad hay un comité de Unidad Popular, de Acción Popular o como quiera que se llame, que en el fondo es quien ejerce el poder. 
En la comisión de los cinco que designó el Consejo del PDC y de la cual formé parte, nos pareció que debía evitarse estos peligros y quien examine el texto de las garantías constitucionales encontrará que en ellas se persigue justamente precaver estos riesgos. Allí se garantiza la existencia de los partidos políticos, la libertad de la gente para organizarse en ellos y el derecho de dichos partidos a participar en todas las elecciones en la generación de los poderes; se garantiza el libre acceso de todas las corrientes de opinión a los medios de comunicación y el derecho de los partidos políticos a mantener medios de comunicación de masas propios; se garantiza el pluralismo ideológico en la enseñanza y la autonomía universitaria: se garantiza que no habrá más Fuerzas Armadas que éstas y el Cuerpo de Carabineros y que éstas tendrán carácter profesional, jerárquico, etc., y no político partidista; finalmente se garantiza que las organizaciones de base de la comunidad deben ser respetadas en su autonomía y libertad y que deben generar democráticamente sus propias autoridades. Con ello, se está tomando una serie de resguardos frente a los métodos típicos de acción que utilizan esos otros sectores para imponer un sistema totalitario y destruir la democracia.

P. -Usted ha hablado de los procedimientos típicos del marxismo cuando llegan al poder. Por muy perfeccionada que esté nuestra Constitución de poco serviría, ya que los comunistas para llevar a cabo sus finalidades, lo primero que hacen es justamente atropellar la Constitución y las leyes, que tanto dicen respetar cuando no tienen el poder.

R. -El problema consiste en que las normas constitucionales, especialmente en estas materias, son muy genéricas. Se dice que todas estas garantías que hemos solicitado ya están en la Constitución; es cierto, pero están en germen, no explicitadas y una disposición genérica se presta para muchas interpretaciones. Un gobierno puede decir, por ejemplo, que no se ha violado la libertad de opinión al negar un espacio en el Canal Nacional de Televisión a un partido de oposición, pero cuando la Constitución señala expresamente que los partidos de oposición tendrán derecho a un espacio en ese canal nacional, el gobierno no podría sostener que no ha violado la Constitución al negar dicho derecho. Es decir, todo el mecanismo ha sido ideado para asegurar la efectividad práctica de las declaraciones genéricas que contiene la Constitución...

\section{P. - ¿Quiere decir que todas estas enmiendas a la Constitución tienen por fin exigir una definición al gobierno de Allende: 0 está dentro de la Constitución 0 está fuera de ella?}

R. -Justamente usted se ha adelantado a algo que le iba a decir. Al establecer estas reglas tan precisas se ha tenido en consideración un segundo objetivo: patentizar -ante todo el país y ante todas las fuerzas que en un momento puedan actuar en el país en defensa de la institucionalidad demo- 
crática- cualquier violación al sistema. Si la norma es muy genérica, puede estar sujeta a interpretaciones y se puede negar que haya habido violaciones, quedando la duda en la ciudadanía entera; pero si la norma es bien precisa y se produce una violación, todo el país y las fuerzas que lo representan y lo cautelan, podrán ver claramente que hubo falta y eso es importante para las posibilidades del sistema de defensa democrático.

Yo he sostenido reiteradamente y lo he dicho en la Junta Nacional, que las garantías constitucionales son, como quien dice, fijar el ring para el combate democrático. Si nos vamos a quedar dormidos sobre estas garantías, adiós democracia: pero si estamos dispuestos a combatir, este ring nos permitirá hacerlo en condiciones de igualdad, tendremos una cancha adecuada para dar con posibilidades de éxito la pelea que en estos momentos es preciso dar en Chile. De eso se trata.

Ahora, volviendo al voto en la Junta del partido. Frente a las respuestas de la Unidad Popular hasta ese momento, fui partidario de que no entráramos a formar parte de la comisión bipartita que, dadas esas respuestas, me hacían pensar que se iba a empantanar en una deliberación larga y en un tira y afloja que no terminaría nunca. Por el contrario, estimé que nosotros, lisa y llanamente, debíamos presentar nuestro propio proyecto, que ya estaba elaborado. Antes de presentarlo, hablaríamos con Allende para incluir o no las observaciones que le mereciera en un plazo de tres o cuatro días; es decir, se trataba de provocar el hecho con o sin observaciones de la Unidad Popular, de la presentación del estatuto de garantías constitucionales en el Parlamento. Según fuera la conducta de Allende y de la Unidad Popular en la discusión de este proyecto el 20 de octubre la Junta Nacional resolvería nuestra posición en el Congreso Pleno.

Estoy convencido que nosotros le prestamos un valioso servicio no sólo al partido, sino a todo el país, con nuestra actitud en la Junta. Sin falsas pretensiones, creo que el éxito espectacular de la comisión bipartita que en menos de 24 horas despachó el proyecto elaborado por nosotros -prácticamente sobre el mismo texto que nosotros preparamos sobre un borrador redactado por mí- se debió en gran medida a que se vio claramente que en la democracia cristiana había una posición de firmeza tal que si no se aceptaba una negociación rápida o si no tenía éxito la comisión, la posición del partido se endurecería extraordinariamente.

P. -Sin embargo, para muchos la actual posición de la DC no significa realmente una alternativa frente al marxismo. Incluso personeros del Partido Nacional han dicho, textualmente, "que ya la DC ha engañado al país durante seis años" porque el gobierno de Frei no habría sido tal alternativa.

R. - He oído tales planteamientos y, lógicamente, discrepo profundamente con ellos. Creo que los hechos demuestran que seguimos siendo la gran 
alternativa, tanto frente al comunismo como frente al capitalismo en Chile. Si uno analiza los resultados de la elección se encuentra con que dos tercios de los chilenos se pronunciaron por postulaciones que aspiran a continuar el proceso de cambios para sustituir al sistema capitalista en Chile: los que votaron por Allende y los que votaron por Tomic. Por otra parte, dos tercios de los chilenos -los que votaron por Alessandri y los que votaron por Tomic- se pronunciaron por mantener las normas tradicionales de convivencia democrática en nuestro país, sobre todo por salvaguardar un régimen de libertad.

Esto significa que en Chile sigue habiendo tres posiciones y hay, prácticamente, un empate social. Hay quienes defienden la libertad y el capitalismo; hay quienes están contra el capitalismo y quieren el socialismo, aun sin libertad. Aunque digan lo contrario, para ellos dentro de su estilo de lucha y de sus métodos de acción política, la libertad es un estorbo, por lo menos durante una etapa. Nosotros en el medio, queremos cambiar el sistema capitalista por una nueva sociedad que denominamos comunitaria, pero queremos hacerlo conservando la libertad.

Estimo que es totalmente válida la frase acuñada por la candidatura de nuestro partido: "si quiere despertar tranquilo el 5 de septiembre, vote por Tomic". La mayoría no quiso tener ese despertar tranquilo pero después de la elección, mucha gente de ambos lados se ha dado cuenta de que verdaderamente cometió un error.

Quienes miran las cosas con criterio inmediatista y quienes están ganados por el miedo -expresiones típicas de lo cual son las decisiones últimas del Partido Nacional, como la "Abstención agresiva" frente a las reformas constitucionales y sus planteamientos en la Junta de ese partido en la semana pasada -tratando de magnificar una imagen de supuesta debilidad de la Democracia Cristiana porque no se atravesó en el camino frente a Allende. ¡Entendámonos bien de qué se trataba! Para mí la cosa era muy clara: El Partido Nacional fue muy categórico al decir que quien obtuviera la primera mayoría debía ser elegido Presidente, aun cuando fuera por un voto, y aun cuando fuera Allende; eso lo dijo Onofre Jarpa, presidente del PN.

Por mi parte puedo decirle que el sábado 5 de septiembre, a las diez de la mañana, fui despertado por un llamado telefónico de provincia, de un dirigente nacional. Me dijo "Mira Patricio lo terrible que ha sucedido. Aquí hay una sola solución: que ustedes voten por Alessandri en el Congreso Pleno, Alessandri renuncia y nosotros apoyamos a un candidato democratacristiano, sea Leighton, Gabriel Valdés o tú mismo, votaríamos por quien pongan ustedes". Esa era la posición en que se colocó el Partido Nacional, contrariando todo lo que había dicho durante la campaña. Sobre la base de esa posición, se le arrancó a don Jorge Alessandri la famosa carta, en la cual mantenía su negativa a asumir la presidencia, pero, en buenas cuentas, aceptaba recibir los 
votos para hacer esta maroma que algunos, usando sus propias expresiones, denominaron "una cuchufleta". Aun cuando estaba medio dormido, porque me había acostado muy tarde, le dije a mi amigo: "Esto es una farsa y una comedia para la cual nosotros no nos podemos prestar".

Sin embargo, esa idea cundió y mucha gente la empezó a trajinar con la esperanza de encontrar alguna solución. Quienes nos regimos en la vida política por principios morales no podríamos aceptar esta fórmula tan burda. Sin embargo, sostuve, incluso en la Junta de mi partido, que no podíamos cerrarnos ninguna puerta. Si la Unidad Popular y Salvador Allende no nos daban garantías efectivas, establecidas en la Constitución, de la preservación de esta cancha de juego, de este ring democrático que le mencionaba antes, no podíamos dejar cerrada esta otra puerta, esta otra posibilidad...

\section{P. - ¿La posibilidad Alessandri?}

R. - La posibilidad Alessandri, pero solo para ese evento, porque nadie puede negociar cerrándose las otras puertas, las otras alternativas. Como la mayoría del partido, siempre pensé que la primera mayoría obtenida por Allende le daba el mejor título y que la mayor afinidad de su programa con el nuestro nos debía conducir a facilitarle su ascensión al Gobierno, siempre que nos diera las garantías que solicitábamos.

\section{P. -Sin embargo, resulta difícil comprender por qué la DC decidió apoyar a Allen- de, a quien era necesario exigir un sinnúmero de garantías democráticas, en lugar de apoyar a Alessandri, a quien no era necesario pedir ninguna garantía.}

R. - La Democracia Cristiana no decidió apoyar a Allende sino una vez que tuvo las seguridades. La orden de partido de votar por Allende en el Congreso Pleno se nos ha dado solamente el martes, luego de aprobarse el estatuto constitucional de garantías democráticas en la Cámara de Diputados y con la certeza de que será aprobado en los mismos términos en el Senado y que en sesenta días más se convertirá en norma constitucional de la República.

Volviendo al argumento de los nacionales, que considero efectista y oportunista, creo que solo se trata del despecho porque no nos dejamos tentar por el señuelo cuando nos ofrecieron seguir gobernando. Eso podría haber traído, para el libre juego democrático del país, consecuencias peores que los riesgos que podemos correr en un gobierno con participación de los sectores extremos del marxismo chileno. La gran mayoría del país entenderá que la posición del Partido Nacional y de la derecha no es en defensa de la libertad y de la democracia, sino en cuanto la libertad y la democracia le permitan defender el sistema capitalista e intereses económicos; su posición no es tanto de alarma por la libertad -aun cuando muchos de ellos honradamente así lo piensan-, sino de defensa de grandes intereses, y el país debe darse cuenta 
de que quienes proceden con este oportunismo están actuando hipócritamente y que tienen algo bajo el poncho, y ese algo es justamente la defensa de los intereses económicos. Nosotros no estamos en política defendiendo esos intereses, sino que estamos defendiendo una concepción sobre lo que debe ser el país, estamos defendiendo el interés de la mayoría de los chilenos y por eso somos una alternativa sólida y seria de un camino democrático para construir en Chile, mediante la participación y el esfuerzo de todos los chilenos, una sociedad al mismo tiempo con justicia y con libertad.

\section{P. -A partir del 4 de noviembre, tanto la DC como los nacionales estarán en la oposición y tendrán, lógicamente, un adversario común que será el gobierno. ¿Daría motivo ello a acciones concretas conjuntas?}

R. -Durante treinta años de vida política hemos actuado sobre la base de un principio fundamental: tenemos algunas verdades, creemos en ellas y luchamos por ellas junto a cualquiera que concuerde con nosotros. Esto ha dado motivo para que muchas veces se nos tilde de veletas y de indefinidos, que vamos de un lado para otro. A veces hemos tenido acciones comunes con la izquierda, y otras, con la derecha, y a lo largo de 35 años no creemos que hayamos sido nosotros los que hemos ido cambiando de un lado para otro. Cuando uno tiene ciertos objetivos y ciertos criterios para cumplirlos, es posible que concurra con otros en el logro de esos objetivos.

En la aspiración de justicia coincidimos más con la izquierda tradicional que con la derecha; en la aspiración de libertad, por lo menos en vastos sectores de la derecha tradicional hay una actitud más respetuosa que en la izquierda, y más concordante con las nuestras. Las elecciones nos situaron, por veredicto del pueblo, en la oposición, pero no haremos con el doctor Allende ni con la Unidad Popular lo que estos hicieron con nuestro Gobierno: negarnos la sal y el agua. Haremos una oposición constructiva y en ella afirmaremos la personalidad de nuestro partido, ratificando nuestros puntos de vista y lo que para nosotros es la verdad y lo mejor para Chile. Esta posición no nos impedirá coincidir con las fuerzas que apoyan a Allende y colaborar con el Congreso al despacho de las iniciativas de ley que sean coincidentes con nuestros puntos de vista. Tampoco estaremos impedidos para coincidir con la oposición del Partido Nacional y las fuerzas de derecha en todos aquellos puntos en que estemos de acuerdo. No creo, sin embargo, que haya una acción concertada y creo que tiene que quedar muy claramente definido qué defienden ellos y qué defendemos nosotros, y ello se verá aún más claro a través de la acción de ambos". 


\section{Fragmento $\mathrm{N}^{\circ} 2$ :}

Diario de Sesiones del Senado, Legislatura 311ª, extraordinaria. Sesión 16a , en jueves 22-X-1970, pp. 583-587.

"[Aylwin se encuentra repasando una por una las garantías establecidas por el Estatuto]

\section{Garantía de la libertad de enseñanza}

En tercer término, el proyecto garantiza la libertad de enseñanza y la autonomía universitaria. El nuevo número 7 del artículo 10 contiene normas de incalculable importancia. En primer lugar, deja en claro que la función primordial del Estado -y por "primordial" se entiende, no que le pertenezca en primer término, sino que es una función, entre las del Estado, de alta prioridad, de gran importancia- se ha de ejercer por un sistema nacional de educación, del cual formen parte no solo las instituciones oficiales de enseñanza, sino también las de índole privada que colaboran en su realización. Este precepto garantiza de un modo en que no lo hace el texto vigente -de modo claro y categórico-, la existencia de la educación particular en Chile. Se trata de los derechos de los habitantes de la República; y este precepto significa que a estos se les reconoce el derecho de escoger el sistema que deseen para la educación de sus hijos: la educación estatal o la educación particular. Y el Estado asegura el funcionamiento de ambas.

Garantiza este precepto la libertad de los establecimientos de enseñanza particular para darse su propia organización y escoger sus autoridades. Garantiza algo más: el deber del Estado de contribuir económicamente a asegurar el funcionamiento de la educación privada y gratuita que no persiga fines de lucro. En esta materia es muy importante tener presente que se entiende por educación gratuita aquella que se da sin cobro en instituciones que no persiguen fines de lucro. Esto no excluye, por lo tanto, las erogaciones voluntarias que los padres de familia quieran hacer para colaborar al mantenimiento de estos colegios, ni la existencia, en el mismo establecimiento, de alumnos que paguen por su educación. De ello quedó constancia en la historia del establecimiento de esta reforma en la Cámara de Diputados y deseamos que conste también aquí. Lo que se excluye es el actual sistema de subvenciones a la enseñanza pagada. La razón de ser de esta interpretación está en que es de justicia que, en un país donde las diferencias entre los niveles de ingresos son todavía muy grandes, los padres de ingresos más altos contribuyan económicamente a educar a sus hijos.

Por otra parte... 
El señor GARCÍA. - ¿Me permite una interrupción, señor Senador?

El señor AYLWIN. - Perdóneme Su Señoría. Quiero terminar la exposición de mis ideas.

Resulta muy beneficioso para el cambio social el que los alumnos que pagan y los que reciben educación gratuita se eduquen en el mismo establecimiento y compartan las mismas experiencias formativas.

Concedo la interrupción que me ha pedido, con cargo a su tiempo, el Honorable señor García.

El señor GARCÍA. - Gracias. Con la venia del señor Presidente.

Entiendo claramente, cuando se deja esa constancia para la historia de la ley, que los pagos voluntarios hechos por los padres de familia no eliminan el carácter de lucro de las universidades. Me interesa saber si son voluntarios los pagos de matrícula en las universidades privadas. A mi juicio, no son voluntarios, sino obligatorios, porque cuando no se cancelan, los alumnos no pueden rendir exámenes.

El señor AYLWIN. - Cuando aborde el problema relativo a las universidades, me referiré a la materia planteada por el Honorable señor García. La verdad es que la norma referente a ellas es enteramente distinta de las establecidas para el resto de la educación.

En cuanto a lo que vengo diciendo, el Diputado señor Maira dejó expresa constancia, en la sesión celebrada por la Comisión de Constitución, Legislación y Justicia de la Cámara, el miércoles 14 de octubre, de que "sólo la educación privada gratuita, que no persiga fines de lucro, recibirá del Estado una contribución económica que garantice su financiamiento. Este principio, en el hecho, ha venido aplicándose en el país en los últimos años, ya que no obstante la disposición legal que establece la obligación de entregar un $25 \%$ del costo por alumno de la educación fiscal para la educación privada pagada, en la práctica, según nos precisó el señor Ministro de Educación, pese a esta disposición legal, desde hace varios años no se ha dado curso a esta obligación, a la que, a su vez, han renunciado a percibir los beneficiarios. Con ello, se ha consagrado una situación de hecho en la cual no se hace efectivo el subsidio estatal a la educación privada pagada, manteniéndose sólo esta ayuda en el caso de la educación privada gratuita.

"Lo que nos manifestaban es lo siguiente: existen establecimientos en los cuales coexisten modalidades de educación gratuita con la educación pagada. Yo les manifesté, y creo que ése es el alcance correcto del texto, que ésta es una disposición que atiende al carácter de la educación que se imparta; haciendo, incluso, las salvedades dentro de determinados establecimientos entre las moda- 
lidades que respecto de él puedan establecerse. Y les manifesté que, a mi juicio, conforme a este texto, en todos aquellos casos en que se impartiera educación gratuita iba a primar la norma constitucional, estableciéndose oportunamente por la autoridad pertinente las precisiones de hecho, y las destinaciones, incluso, dentro de un mismo establecimiento ubicado en la provincia".

El señor Luis Maira, quien ofició en la Sala de Diputado informante, textualmente dijo lo siguiente: "Se consagra el principio de que sólo la educación privada gratuita y que no persiga fines de lucro recibirá una contribución económica que garantice su financiamiento; idea que como ha quedado establecido en las actas de la Comisión, tendrá aplicación incluso en los establecimientos de carácter mixto, como por ejemplo en algunos en los cuales la educación básica es gratuita, y la secundaria, pagada; en casos como éste y en todo el ámbito de la educación efectivamente gratuita y que no persiga fines de lucro, tendrá lugar la aplicación de las disposiciones que se consagran".

Lo mismo hizo el Diputado señor César Fuentes en los debates de la Cámara.

Aparte lo anterior, se garantiza el carácter democrático y pluralista de la educación en todo su sistema, tanto estatal como particular, y se elimina la posibilidad de que tenga una orientación partidaria oficial. Se garantiza que la renovación de los programas, o la organización del sistema educacional, ha de estudiarse y decidirse por instituciones competentes, de composición pluralista.

Se establece que la Superintendencia de Educación la dirigirá un Consejo integrado por representantes de todos los sectores vinculados al sistema nacional de educación, y que la representación de ellos se generará democráticamente, vale decir, no solamente por ciertos sectores.

Además, se consignan normas para garantizar que la selección de textos de estudio se realice sobre la base de concursos públicos, a los cuales tengan acceso todos los educadores idóneos, cualquiera que sea su ideología; que existan facilidades equitativas para editar y difundir los textos escolares, y que los establecimientos educacionales tengan libertad para elegir los que prefieran. Lo anterior se relaciona con el sistema educacional básico y secundario, es decir, con la enseñanza básica, media y parvularia.

\section{Garantía de la autonomía universitaria}

Las normas siguientes se refieren a la autonomía universitaria, que no está limitada por las anteriores.

Se consagra que las universidades estatales y particulares son personas jurídicas dotadas de autonomía académica, administrativa y económica, y que corresponde al Estado proveer a su adecuado financiamiento para que 
puedan cumplir sus funciones, de acuerdo con los requerimientos educacionales, científicos y culturales del país.

Lo expuesto se refiere tanto a las universidades estatales como a las particulares. En consecuencia, la afirmación hecha por el Honorable señor Bulnes Sanfuentes proviene de una interpretación errónea o de un desconocimiento del verdadero sentido y del claro texto del precepto constitucional, porque él asegura tanto a las universidades estatales como a las particulares, sin condicionarlas al no cobro de ningún beneficio o ingreso a los estudiantes por sus servicios, la obligación del Estado de proveer a su adecuado financiamiento, a fin de que puedan cumplir plenamente sus funciones.

El señor BULNES SANFUENTES. - ¿Me permite una interrupción con cargo a nuestro tiempo?

El señor AYLWIN. -Con todo gusto.

El señor BULNES SANFUENTES. - En primer lugar, la disposición referente a la educación particular, que prohíbe subvencionar a los planteles pagados, es aplicable a todos los establecimientos educacionales básicos, medios o superiores, porque un axioma de derecho dice que "cuando la ley no distingue, no le es lícito al intérprete distinguir". No hace distingo de la educación universitaria.

En segundo término, el precepto que dispone que se deberá proveer al adecuado financiamiento de las universidades es un consejo al legislador. El legislador determinará qué es lo adecuado, y podrá establecer, por ejemplo, que la universidad disponga de la quinta parte del alumnado que actualmente tiene o que no lo amplíe, y concederle subvención sólo para cumplir sus fines con esos alumnos.

De manera que las observaciones que hice sobre este precepto, que considero gravísimas, se han confirmado.

El señor AYLWIN. -En verdad, me sorprenden las palabras que acabamos de oír al Honorable señor Bulnes Sanfuentes. Parece que Su Señoría -perdóneme que se lo diga con franqueza-, más que preocuparse por obtener la interpretación que corresponde, porque sus autores -yo redacté el borrador de este proyecto- le están diciendo cuál es su verdadera intención, pretende buscar, con ánimo mezquino y partidista, una interpretación en perjuicio de las universidades particulares, a las cuales debería defender. Pero dejo constancia de que su interpretación no corresponde a la verdad.

Deseo dejar en claro ante el Senado que, además del axioma de que "cuando la ley no distingue, no le es lícito al intérprete distinguir", hay otro consagrado expresamente en las normas sobre interpretación de las 
leyes, que establece que "las disposiciones particulares sobre determinadas materias prevalecen sobre las disposiciones generales de la misma ley". En este momento estamos examinando las disposiciones particulares referentes a las universidades. Y la norma es categórica, porque consagra para todas las universidades, tanto estatales como particulares, el derecho de que el Estado provea, a su adecuado financiamiento, a fin de que puedan cumplir plenamente sus funciones.

Más todavía: el precepto garantiza el acceso a las universidades sobre la base exclusiva de la idoneidad de los postulantes, para evitar discriminaciones ideológicas o de otro carácter, que puedan perjudicar su democrática generación. A la vez, se exige que quienes ingresan a la universidad sean egresados de la enseñanza media o tengan estudios equivalentes, a fin de impedir que se dé el nombre de universidades a instituciones fantasmas, a las cuales pueda llegar gente sin capacidad para recibir enseñanza superior.

Hay algo más sobre la materia. Esta norma constitucional garantiza el pluralismo dentro de las universidades, como carácter esencial de ella. Y sus incisos finales, al establecer que el personal académico es libre para desarrollar las materias, conforme a sus ideas; que tendrá la obligación de ofrecer a sus alumnos la información necesaria sobre las doctrinas y los principios diferentes y discrepantes, y que los estudiantes universitarios tienen derecho a expresar sus propias ideas y a elegir los profesores y la enseñanza que deseen, garantizan un régimen democrático dentro de la universidad.

Tal garantía es necesaria frente a los hechos que han empezado a manifestarse en algunas universidades chilenas; por ejemplo, unas jornadas pedagógicas celebradas en la Universidad Técnica del Estado. Hoy día, la juventud de la Democracia Cristiana denunció, por medio de la prensa, que en esas jornadas, con participación de las autoridades de ese plantel universitario y suspensión de las clases, se pretendió imponer asistencia obligatoria y dictar clases de marxismo a los alumnos. Actuaciones como éstas, que evidentemente constituyen un abuso y vulneran el pluralismo propio de la universidad, quedan excluidas por esta reforma constitucional".

\section{Fragmento $\mathrm{N}^{\circ} 3$ :}

Diario de Sesiones del Senado, Legislatura 317a , extraordinaria. Sesión $3^{a}$, en viernes 6-X-1972, pp. 321-327.

"El señor AYLWIN. -Deseo decir solo dos cosas a propósito de las interrupciones que se me solicitaron.

Primero, que no es a los democratacristianos a quienes se podría acusar de falta de disposición al diálogo con el actual Gobierno de la República. 


\section{El señor TEITELBOIM. - ¡A algunos!}

El señor AYLWIN. -En general, a la Democracia Cristiana; porque no aceptamos que se siga pretendiendo dividir a los democratacristianos en buenos y malos, calificando a uno hoy día de bueno, y mañana de malo, según le guste o no le guste al Honorable señor Teitelboim.

El señor TEITELBOIM. ¡Es usted el que se define! Usted es contrario al diálogo, por todo lo que ha dicho esta mañana.

El señor PALMA (Presidente). - Honorable señor Teitelboim, está con la palabra el Honorable señor Aylwin.

El señor A YLWIN. -Puedo probar a Su Señoría que he sido partidario del diálogo. Desde luego, participé en el que generó el Estatuto de Garantías Constitucionales que permitió elegir al señor Allende como Presidente de la República, y dialogué con él. En reiteradas oportunidades todos los democratacristianos -el Senador que habla, entre ellos- hemos estado dispuestos a conversar, y así lo hemos hecho; pero, Senador señor Teitelboim -quiero decirlo con voz tranquila, pero muy firme--, estamos cansados de ser engañados. Uno puede soportar que le mientan una vez, pero cuando le faltan a la verdad dos, tres, cuatro, cinco, diez veces, entonces uno ya no cree.

El señor TEITELBOIM. - ¡Se cierra el diálogo!

El señor AYLWIN. Para dialogar, se necesita tener un mínimo de fe en el contradictor.

El señor TEITELBOIM. - ¡Hombre de poca fe...!

El señor AYLWIN. - Voy a dar pruebas de lo que estoy diciendo.

El señor PALMA (Presidente) - . ¡Honorable señor Teitelboim, tendré que llamar al orden a Su Señoría!

El señor AYLWIN. -En cuanto a las observaciones del Honorable señor Gumucio, solo quiero recordar, primero, que la afirmación que el señor Senador hace, contenida en una carta del señor Ministro de Justicia, don Jorge Tapia, donde se da como un hecho cierto la concertación de determinados acuerdos, fue categórica y terminantemente desmentida en esta misma Sala por el Presidente del Partido Demócrata Cristiano, Senador Fuentealba.

Segundo, que la famosa historia del Instituto del Papel no pasa de ser un mecanismo que, a nuestro juicio, no ofrece garantías suficientes, porque sería una entidad meramente distribuidora, y bastaría que la empresa productora, por cualquier medio, por cualquier artificio, no entregara el papel, para que las funciones de ese instituto fueran meramente ilusorias. 
¿Qué queda en claro de todo lo que he expuesto? Sin ser suspicaz, simplemente, siguiendo la lógica racional de los hechos, quien juzgue con mediana inteligencia el proceso que estamos viviendo podrá deducir que se procura hacer quebrar a la Compañía Manufacturera de Papeles y Cartones para estatificarla; que, con esa medida, se persigue controlar los diarios e imprentas condicionándoseles la entrega del papel, y que, finalmente, se persigue coartar la libertad del proceso electoral de marzo próximo.

Hay precedentes históricos en esta materia. En Checoslovaquia debían realizarse elecciones en mayo de 1948. El Partido Social Demócrata del Presidente Benes y su Ministro Masaryk y los demás partidos que integraban la coalición de Gobierno, pero que discrepaban de los métodos del Partido Comunista, se organizaron para dar la campaña y ganar esas elecciones. Y cuando se apresuraban a hacerlo y la campaña se iba presentando con caracteres favorables para ellos, sobrevino lo que se ha llamado "el golpe de Praga", en febrero o marzo de ese año 1948. ¿Cuál fue el instrumento decisivo en ese golpe? La toma, por funcionarios de Gobierno, de todas las radios, y la negativa de los sindicatos que controlaban la producción papelera a entregar este elemento a todos los diarios de la Oposición. De la noche a la mañana, los elementos opositores se encontraron con que estaban silenciados y que no podían exponer sus puntos de vista ante el país. A los pocos días, con la presión del Ejército Rojo en las fronteras, esas medidas se tradujeron en la toma total del poder en ese país por el comunismo.

Estos no son cuentos. Es historia. Y, frente a ello, quiero terminar recordando algunos antecedentes que me parece indispensable tener presente.

\section{Compromisos violados}

En esta Sala se aprobó el Estatuto de Garantías Constitucionales. Entre ellas se estableció la del número 3 del artículo 10, relacionada con la libertad de opinión, que, entre otras cosas, tiende a asegurar la no discriminación en la venta o suministro a los diarios, periódicos, editoriales, revistas, radiodifusoras y estaciones de televisión, de papel, tinta, maquinaria y otros elementos de trabajo. Esa norma establece que sólo por ley se puede regular el régimen de los medios de comunicación.

Conviene tener presente lo que se dijo en la carta cambiada entre el Partido Demócrata Cristiano, presidido en aquella época por nuestro colega Benjamín Prado, y el entonces Senador Allende. En el memorándum del Senador Prado, del Partido Demócrata Cristiano, se señaló lo siguiente:

"La consagración constitucional de un Estatuto de los medios de comunicación que asegure el libre acceso a la prensa, la radio y la televisión de todas las corrientes de opinión, en igualdad de condi- 
ciones, reservando a la ley la modificación del régimen de propiedad de estos medios. Solo en virtud de una ley se podrá determinar el régimen, de importación y comercialización de libros, papel y demás elementos necesarios para la operación de los medios de difusión impresos, orales y visuales".

¿Qué contestó el actual Presidente, entonces Senador Allende? Dijo que el derecho de todos los partidos a contar con medios propios e inviolables para su funcionamiento y difusión, y la oportunidad de acceso a los medios de comunicación" eran, a su juicio, una garantía indispensable de la democracia. Y agregó: "La libre divulgación de las ideas, a través de todos los medios de difusión -libros, prensa, radio, televisión- ha sido un principio que hemos defendido en forma invariable, como continuaremos haciéndolo. En este campo hemos evidenciado concretamente nuestra posición al tratarse, por ejemplo, el régimen de la televisión nacional, propugnando la consagración de disposiciones que cautelan su rol democrático y no excluyente".

Todos sabemos lo que ha pasado después con la Televisión Nacional, que desmiente esas palabras del Presidente de la República.

Pues bien, frente a ello, ¿cuál era la opinión del Partido Socialista sobre el Estatuto de Garantías Democráticas? En los acuerdos del Vigesimotercer Congreso realizado por esa colectividad en enero de 1971, se dice que: "el Gobierno desenvuelve su acción entrabada por la institucionalidad burguesa". Es decir, la institucionalidad es meramente una traba para la acción del Gobierno. Además, se señala que, frente al advenimiento del actual Gobierno, algunos -éstos somos los democratacristianos- "buscaron ganar tiempo, bloquear el cumplimiento del programa e inmovilizar al Gobierno popular tras la exigencia de las llamadas 'garantías democráticas'".

Esto marca el espíritu con que el Partido Socialista y muchos hombres de Gobierno han entendido las mencionadas garantías y nuestra exigencia de respeto a la Constitución y a la ley. ¿Para qué voy a recordar todas las promesas incumplidas? ¿Por qué hemos perdido la fe?

Porque en enero de 1971 oímos al Presidente de la República anunciar un proyecto de ley para nacionalizar la banca, pero esa iniciativa no llegó jamás al Congreso, y se procedió a estatificar la banca de hecho, por medios ilegales.

Porque el Presidente de la República me envió una carta a mí, en abril de 1971, siendo yo Presidente del Senado, declarando que la reforma agraria se haría en todo conforme a la ley y que se procedería a la asignación de tierras a los campesinos. Y esas promesas, en año y medio no han sido cumplidas.

Porque el Primer Mandatario se comprometió con nosotros a que mientras no se despachara el proyecto sobre las áreas de la economía, se paralizaría 
el proceso de estatificaciones de hecho, por la vía ilegal de la intervención y de la requisición. Y esa promesa no fue cumplida.

Porque el Jefe del Estado se comprometió con la Democracia Cristiana a restablecer en su cargo a los obreros despedidos de Sumar. Y su palabra no fue cumplida. Esos trabajadores siguen despedidos de esa fábrica.

Porque el Presidente de la República se ha jactado ante Chile y ante el mundo de su respeto a la libertad de reunión y al derecho de expresión; pero ha tolerado la acción de funcionarios de su exclusiva confianza -Ministros, Gobernadores e Intendentes- que niegan permiso a la Oposición para desfilar, mientras lo conceden a los partidos de Gobierno; además, clausuran ilegalmente medios de expresión de la Oposición. Más aún, el Jefe del Estado se ha hecho responsable de actuaciones del Canal Nacional de Televisión que contradicen totalmente sus promesas de pluralismo y democracia.

\section{¿Regla moral o necesidad táctica?}

Aquí, en esta Sala, antes de ser elegido y designado Presidente de la República, cuando discutíamos el Estatuto de Garantías Democráticas, el Honorable señor Allende, con la voz más engolada y solemne de que es capaz, dijo lo siguiente: "He venido a decir que estas disposiciones deben entenderse, no sólo como principios consagrados en la Carta Fundamental, sino como la regla moral de un compromiso ante nuestra propia conciencia y ante la historia". Eso ocurrió en octubre de 1970.

En febrero de 1971, tres meses después, entrevistado por Régis Debray -documento publicado en Punto Final en marzo de 1971, y al cual me he referido varias veces-, ante la pregunta de si "¿Era absolutamente necesario? ¿Era imprescindible negociar este Estatuto de Garantías Democráticas?", el señor Allende contesta: "Sí, por eso lo hicimos. Sigo convencido de que fue correcto producir ese Estatuto de Garantías, pero es conveniente aclarar que no es justo usar la palabra "negociación", por cuanto nosotros no cedimos una línea de nuestro programa de Gobierno. Ubícate en el período en que se produjo ese Estatuto y lo medirás como una necesidad táctica". Y termina el párrafo diciendo: "En ese momento lo importante era tomar el Gobierno".

Yo pregunto al Senado, yo pregunto a Chile, ¿en qué quedamos? ¿Regla moral ante la conciencia y ante la historia? ¿O necesidad táctica? ¡Que juzgue Chile entero cuál es la moral del señor Presidente de la República!

El señor MONTES. -Esa es una suprema insolencia... 
El señor AYLWIN. -No le he concedido ninguna interrupción, señor Senador. Quiero terminar, pero antes concedo una interrupción al Honorable señor Baltra, si la Sala me lo permite.

El señor TEITELBOIM. - ¿Cuánto tiempo le falta?

El señor PALMA (Presidente). -El señor Senador tiene derecho a usar de su tiempo. No lo ha ocupado por entero todavía, y está inscrito desde ayer.

El señor TEITELBOIM. -Señor Presidente, jaquí sólo hablarán los opositores al Gobierno, y esto en nombre de la libertad de expresión! No se permitirá que la Izquierda hable. ¡Tal es el pluralismo de esta casa! Y, por si fuera poco, el señor Aylwin se dedica a conceder nuevas interrupciones.

El señor PALMA (Presidente). -Los señores Senadores se inscribieron ayer.

El señor AYLWIN. Termino, señor Presidente, como lo anuncié.

El señor TEITELBOIM. - ¿Cuándo va a terminar? ¡Parece que le cuesta terminar!

El señor AYLWIN. -No voy a seguir a Su Señoría en sus chistes de mala clase.

El señor TEITELBOIM. -Ha anunciado varias veces que va a terminar. Lo he escuchado por lo menos cinco veces decir lo mismo.

El señor AYLWIN.- Y si quiero sigo, señor Teitelboim.

El señor TEITELBOIM. - Muy bien, está en su derecho.

¿Cuánto tiempo tiene aún el señor Senador para hablar?

El señor PALMA (Presidente). - Todavía puede usar de la palabra por veinte minutos más.

El señor AYLWIN. -No voy a hablar veinte minutos más.

\section{Régimen de ilegalidad}

Como vía de conclusión, yo quiero señalar claramente tres cosas, que creo que interpretan la gran preocupación del Partido Demócrata Cristiano, de todas las fuerzas de Oposición y de la gran mayoría de Chile, frente a la situación que estamos analizando. 
Primero: estamos en presencia de un caso manifiesto de inconstitucionalidad e ilegalidad, de lo que en derecho se llama desviación de poder. Las atribuciones que las leyes otorgan a las autoridades, conforme al principio de que ninguna autoridad puede hacer otra cosa que la que expresamente se le faculta por la ley para hacer, consagrada en el artículo 49 de la Constitución, se conceden en función de determinados fines tenidos en vista por el legislador. Toda la legislación económica relativa a la fijación de precios y al abastecimiento de artículos de primera necesidad tiene por objeto proveer las más convenientes condiciones económicas de vida de la población, según lo dice expresamente la ley, en lo referente al abastecimiento de artículos de consumo o de bienes para satisfacer sus necesidades.

Pues bien, cuando atribuciones que se han concedido para un fin son usadas para otro fin, se desvía la ley, se abusa del Poder. Y esto, en el Estado de derecho, está sancionado con la nulidad del acto. Por eso la Contraloría General de la República ha declarado ilegales dichos actos y, por lo mismo, si en Chile hubiera tribunales administrativos, como los hay en la mayor parte de los países democráticos del mundo, tales actos serían anulados, por desviación de poder.

El señor LUENGO. -Su Señoría podría referirse al Tribunal Constitucional.

El señor AYLWIN. - El Tribunal Constitucional no tiene competencia en la materia, y muy bien lo sabe Su Señoría.

No voy a entrar a discutir ese tema adjetivo.

En segundo término, esas inconstitucionalidades e ilegalidades, junto con las que se están cometiendo con los medios de comunicación de masas, con el abuso de la Televisión Nacional, con las clausuras ilegales de radios y con las limitaciones al derecho de reunión, están colmando la medida de la paciencia cívica de este país, porque constituyen la más grave amenaza a la libertad de información, a la libre expresión democrática y a la posibilidad de realizar en marzo próximo un proceso eleccionario que se desenvuelva dentro de cauces efectivos de libertad. Nada sacamos con que el Gobierno nos hable de libertad y de que el día de los comicios va a permitir que todos vayamos a sufragar libremente, si no se garantiza -y ésta es una responsabilidad fundamental del Gobierno en la hora presente- la libertad efectiva del proceso electoral mediante el libre acceso de todas las fuerzas políticas a los medios de comunicación.

El señor MONTES. - ¿Me concedería una interrupción, señor Senador?

El señor AYLWIN. -No, señor Senador. 
En tercer lugar -y con esto termino-, eso coloca al actual régimen, el que preside el señor Allende, en un plano de franca ilegitimidad. Un Gobierno puede nacer legítimo, y el actual nació legítimo, por la sanción que le dio el Congreso Pleno, reunido solemnemente aquí, en el palacio donde nos encontramos. Porque aquí lo elegimos la mayoría de los congresales, el señor Allende es Presidente de Chile, y su legitimidad deriva precisamente de la legítima expresión del Congreso Pleno. Pero un Gobierno que nace legítimo puede devenir en ilegítimo si cae en la pendiente de la inconstitucionalidad y la ilegalidad permanentes, del atropello sistemático a la ley. Y lo que se pretende hoy día es acostumbrar a los chilenos a soportar pacientemente -0 amedrentarlos, para que se acobarden-este régimen de inconstitucionalidad, de ilegalidad y de arbitrariedad.

Nosotros tenemos el deber de denunciar estos hechos públicamente ante el país y de pedir que se transcriban estas observaciones al señor Presidente de la República, lo que termino solicitando".

\section{Fragmento $\mathrm{N}^{\circ} 4$ :}

Diario de Sesiones del Senado, Legislatura 318a, ordinaria. Sesión 23a , en viernes 29-VI-1973, pp. 1030-1031.

"El señor FREI (Presidente).- Antes de ofrecer la palabra sobre el tema a que fue citada esta sesión, debo dar cuenta a la Sala de que el Honorable señor Jerez me comunicó oficialmente la voluntad de los Senadores de la Unidad Popular, a petición de los cuales se convocó a esta sesión, de que ella no se verificara. Como esta solicitud se formuló fuera del plazo reglamentario, a la Mesa solo le correspondía abrir la sesión. He dado a conocer esta comunicación para anular la sesión, aun cuando reglamentariamente no procedía aceptarla.

Están inscritos los Honorables señores Rodríguez, Montes -quien renuncia a usar de la palabra- y Jerez.

Ofrezco la palabra.

El señor AYLWIN. -Pido la palabra.

El señor AGUIRRE DOOLAN. - Me inscribe en seguida, señor Presidente.

El señor FREI (Presidente). - Tiene la palabra el Honorable señor Aylwin.

El señor AYLWIN. -Señor Presidente, los Senadores democratacristianos hemos concurrido a esta sesión cumpliendo nuestro deber. Creemos que, si 
ella fue convocada, debíamos estar aquí en este recinto, que es expresión de la democracia chilena, para manifestar nuestra opinión.

La ausencia muy explicable de los señores Ministros de Estado no nos permite contar con los antecedentes necesarios para emitir un juicio sobre lo que está aconteciendo. En todo caso, nosotros queremos dejar testimonio una vez más de la permanente adhesión de la Democracia Cristiana al sistema institucional chileno y, en consecuencia, de su convicción de que son métodos constitucionales, legales y democráticos los que deben siempre imperar, y de nuestro repudio a cualquiera acción que se salga de estos moldes.

Consecuentes con esto, a las 11 de la mañana el Secretario General de nuestro partido, Diputado Eduardo Cerda, por acuerdo de la Mesa, emitió una declaración fijando estos principios de siempre de la Democracia Cristiana.

Por mi parte, pedí una comunicación telefónica con el señor Presidente de la República, la que logré sólo a un cuarto para las tres, para expresarle que, desde nuestra actitud de oposición al Gobierno, que mantenemos por razones que no es del caso reiterar aquí, reafirmamos en este instante nuestra adhesión al sistema institucional chileno".

\section{Fragmento $\mathrm{N}^{\circ} 5$ :}

"Aylwin cuenta: Lo que pasó y lo que viene", en Qué Pasa, 121, 9-VIII-1973, pp. $7-10$.

"'Solo yo, Presidente, que tengo en mi partido fama de ser un decidido opositor suyo, podía venir a hablar con Ud., a cualquier otro no le hubieran creído y hasta lo habrían echado'.

Así resumió Patricio Aylwin para Allende su paradoja personal de durodialogante.

Así vio Patricio Aylwin para QUÉ PASA el diálogo... y lo que vendrá:

- El diálogo está terminado. Fue en dos planos; hablamos dos lenguajes distintos.

- Nuestros puntos de vista los planteamos muy claramente, antes de ser invitados por el Presidente. Cuando concurrimos, dimos por supuesto que él, conociéndolos, estaría dispuesto a llevar el debate en ese terreno. 
- Lo primero, a nuestro juicio, era tener respeto a la Constitución y a las leyes; suprimir los grupos armados; poner fin a las tomas y promulgar las reformas constitucionales aprobadas por el Congreso.

- Le dijimos al Presidente: el país está cansado de oírnos decir a Ud. y a los políticos en general que las cosas se van a hacer conforme a la ley y que esto no se cumpla. Ud. dice que no haya más ejército que las Fuerzas Armadas, pero en el hecho surgen ejércitos paralelos. Ud. dice que no desea las tomas, pero las tomas continúan. Queremos que $\mathrm{Ud}$. tenga un gabinete que haga cumplir lo que Ud. manda (Aylwin recordó a Allende su promesa al senador Olguín, allí presente, de reincorporar a los 38 despedidos de SUMAR, las promesas del Ministro Prats a los transportistas en 1972 y la del Ministro Briones a los despedidos de El Teniente... todas incumplidas).

- ¿El futuro? No habiéndose concretado la tregua, sigue vigente el claro mandato de la Junta Nacional: ejercer todos los recursos constitucionales, legales y derivados de nuestro poder en la base social para reestablecer el normal y democrático funcionamiento de las instituciones.

Así, por ejemplo, el ministro Cademártori tendrá que pronunciarse respecto al mismo emplazamiento que hicimos a su antecesor, señor Millas (Nota de QUÉ PASA: dicho emplazamiento llevó a la destitución de Millas).

Pero honestamente no creo que lo anterior baste: es necesario además una movilización mucho más enérgica en la base social. Hasta ahora hemos estado conteniendo a una serie de gremios - de trabajadores, no empresariales- que se hallan desesperados y quieren manifestarse de distintas formas. Creo que los respaldaremos con toda decisión. Y procuraremos coordinar la acción de todos los sectores políticos, sindicales y gremiales que quieren reestablecer en Chile un régimen de normalidad institucional". 


\section{Referencias biliográficas}

a) Artículos y capítulos de libros

Arriagada, G. (2003). "La crisis de la UP y la República de 1925", en R. Baño (ed.), La Unidad Popular treinta años después, Santiago: LOM Ediciones, pp. 129-142.

Hurtado Torres, S. (2013). "El Golpe que no fue: Eduardo Frei, la Democracia Cristiana y la elección presidencial de 1970", en Estudios Públicos, № 129, pp. 105-140.

Silva Cimma, E. (2008). "El Tribunal Constitucional de Chile (1971-1973)", en Cuadernos del Tribunal Constitucional, № 38.

b) Libros

Aylwin Azócar, P. (1998). El Reencuentro de los Demócratas. Del Golpe al triunfo del No. Santiago: Ediciones B.

Donoso Pacheco, J. y G. D. Echeverría (2013). Los 13 del 13. Los DC contra el golpe. Santiago: RIL Editores.

Fermandois, J. (2013). La Revolución inconclusa. La izquierda chilena y el gobierno de la Unidad Popular. Santiago: Centro de Estudios Públicos.

González, M. (2012). La conjura. Los mil y un días del golpe. Santiago: Editorial Catalonia.

Gaddis, J. L. (2005). The Cold War: A New History. London: Penguin Books.

Prats González, C. (1987). Memorias. Testimonios de un soldado. Santiago: Pehuén Editores.

Serrano, M. y A. Cavallo (2006). El poder de la paradoja. 14 lecciones políticas de la vida de Patricio Aylwin, Santiago: Grupo Editorial Norma.

Valenzuela, A. (1989). El quiebre de la democracia en Chile, Santiago: FLACSO. 